\title{
PROYECTO DE OBRAS DE RESTAURACION EN LA GRANJA DE SAN ILDEFONSO/SEGOVIA/ESPAÑA
}

\author{
(RESTAURATION WORKS PROJECT IN GRANJA DE SAN ILDEFONSO/SEGOVIAISPAIN)
}

Ignacio de las Casas Gómez, Arquitecto

$128-23$

\section{RESUMEN}

Dentro de una tipología industrial, la Real Fábrica de Cristales de la Granja presenta la peculiaridad de ser una construcción neoclásica, caracterizada por su nave central rematada por dos cúpulas a modo de planta basilical.

La actuación emprendida tiene por fin frenar el proceso de deterioro y dar cabida en el edificio al Centro Nacional del Vidrio. Para ello se han reconstruido fundamentalmente cubiertas y bóvedas, con especial cuidado en el diseño de los distintos tipos de cerchas.
SUMMARY

The "Real Fábrica de Cristales de la Granja" (Glass Royal Factory) is an industrial building, presenting the special feature of its style, Neo-Classicism. It is characterized by its central nave finished on two domes in the manner of basilical plan.

The begun works have a purpose: to break the spoiling process and make room for the Glass National Center. In order to do it, roofs and vaults have been reconstructed. The design of roof truss types is stressed.

\section{INTRODUCCION}

El edificio de la Real Fábrica de Cristales de la Granja de San Ildefonso fue construido a finales del siglo XVIII por D. José Díaz Gamones, bajo la supervisión de D. José de Villanueva. Es junto a la Fábrica de Tabacos de Sevilla y la de Sedas de Talavera de la Reina uno de los primeros edificios proyectados con una tipologia netamente industrial.

Tras dos incendios ocurridos en las antiguas fábricas fundadas por Felipe $V$ a imagen de las fábricas de Saint Gobain en Paris se decide construir una fábrica realizada con materiales, en cuanto a las salas de hornos se refiere, que no puedieran de nuevo ser pasto de las llamas. Asi pues se construye con piedra y ladrillo resolviendo las grandes luces con arcos, bóvedas y cúpulas, todo ello dentro de las premisas básicas de las construcciones neoclásicas.

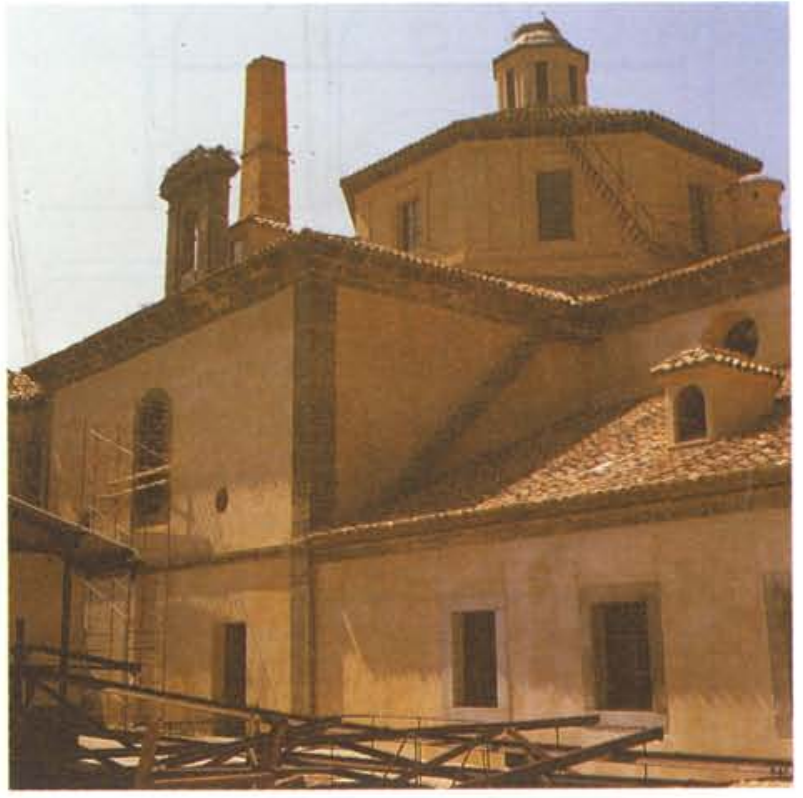

Exterior cúpula nave principal. 


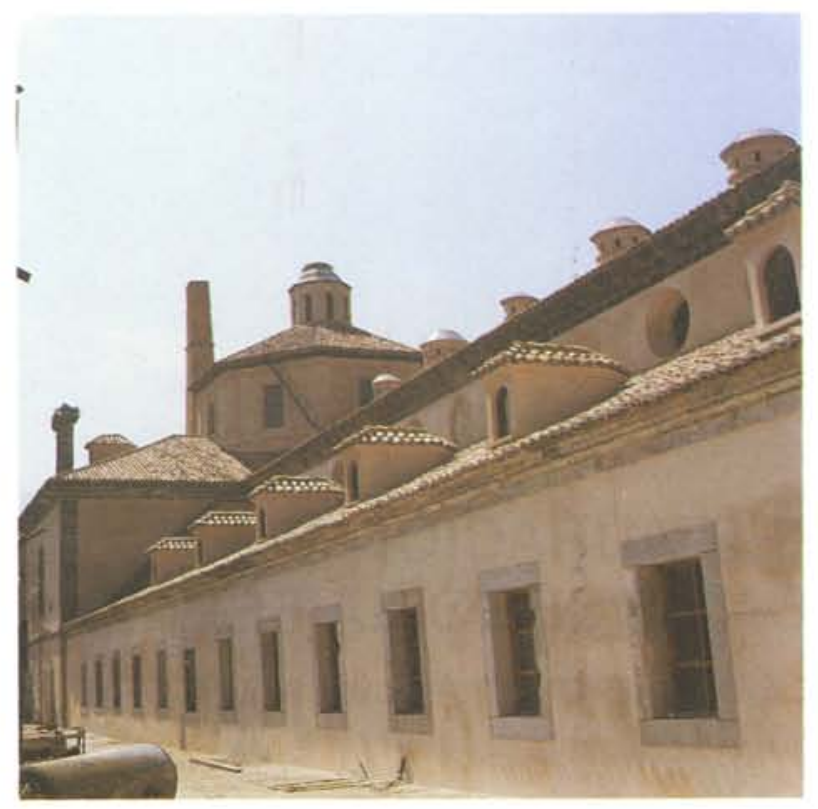

Fachada nave principal.

El edificio consta de una nave fundamental con una bóveda de cañón que remata en dos cúpulas a modo de planta basilical duplicada. En estos espacios se situaban los hornos de fundición y accediendo desde la bóveda central se situan a 30 carquesas (hornos de reco- cido). El resto de las naves perpendiculares o paralelas a ésta son para el proceso de molido, mezclas, secado de madera y fabricación del material refractario, bordeando el edificio los talleres de acabado de las pie. zas en plantas bajas y viviendas en las altas.

La Fábrica ha sido explotada de forma casi continua hasta el año 70 en que quedó vacia y sufrió a lo largo de su historia varias transformaciones debido fundamentalmente al cambio de sistemas de energía; en primer lugar los hornos funcionaban con leña, después se crean hornos para la fabricación de gas y más tarde se trabajará con gas-oil.
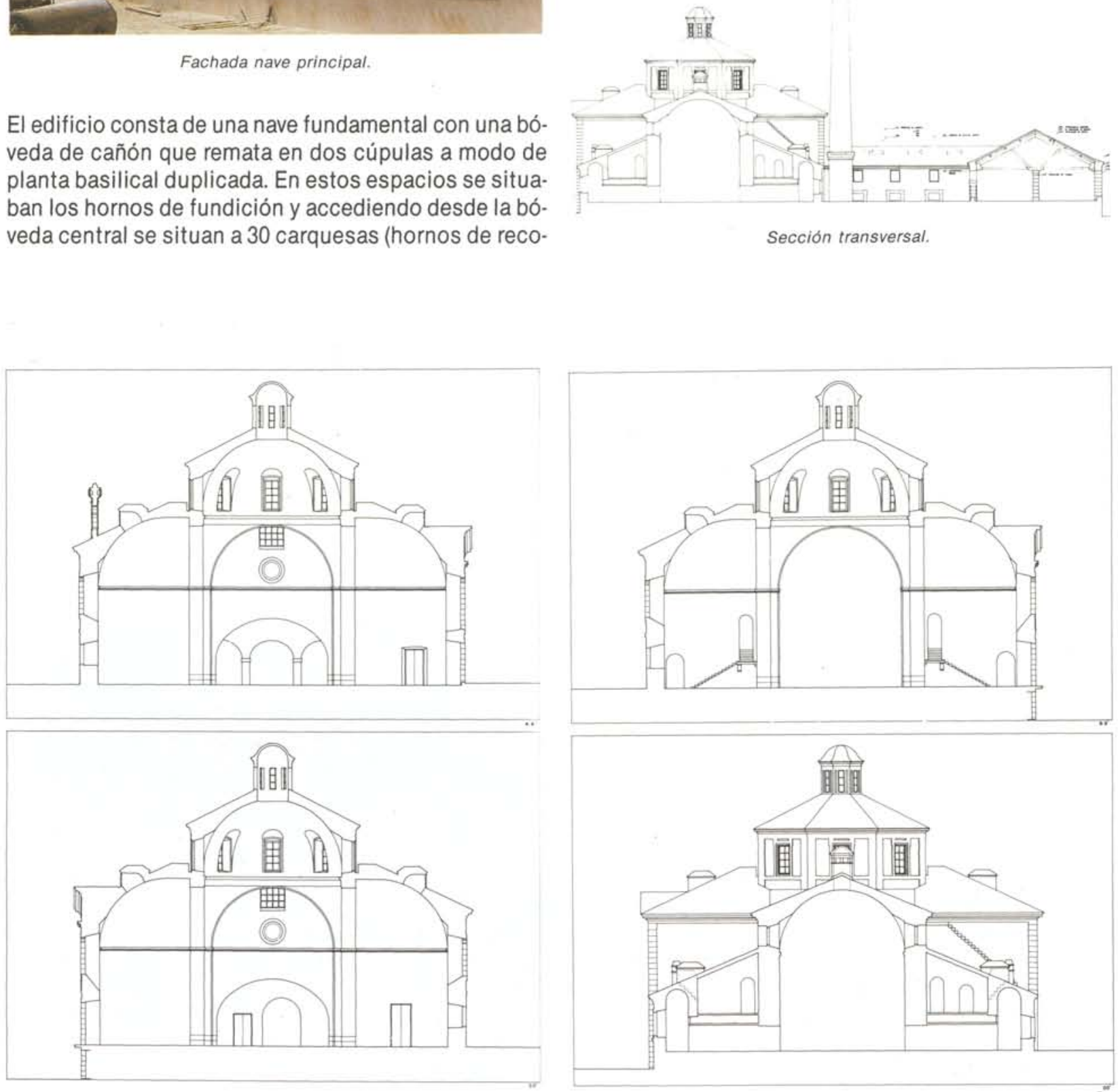


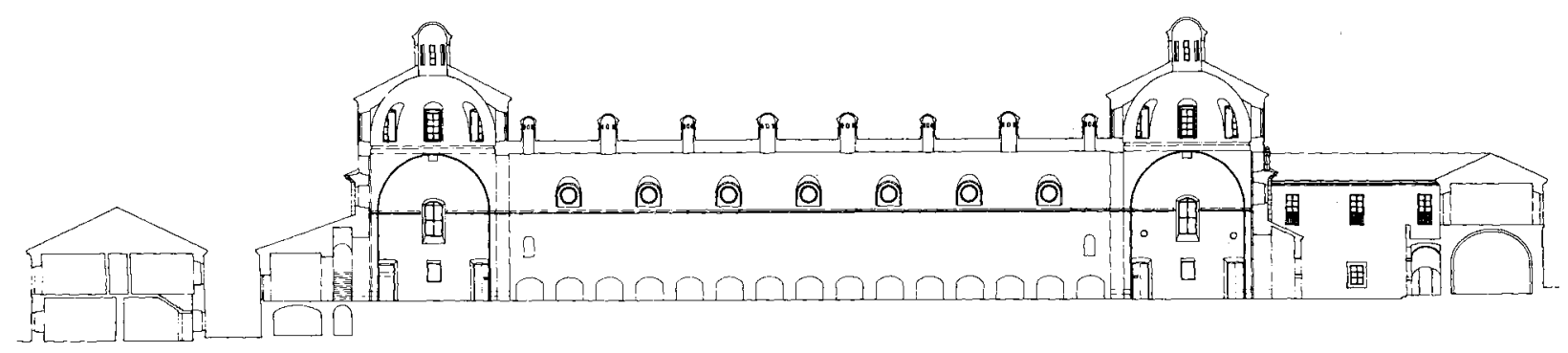

Sección longitudinal.

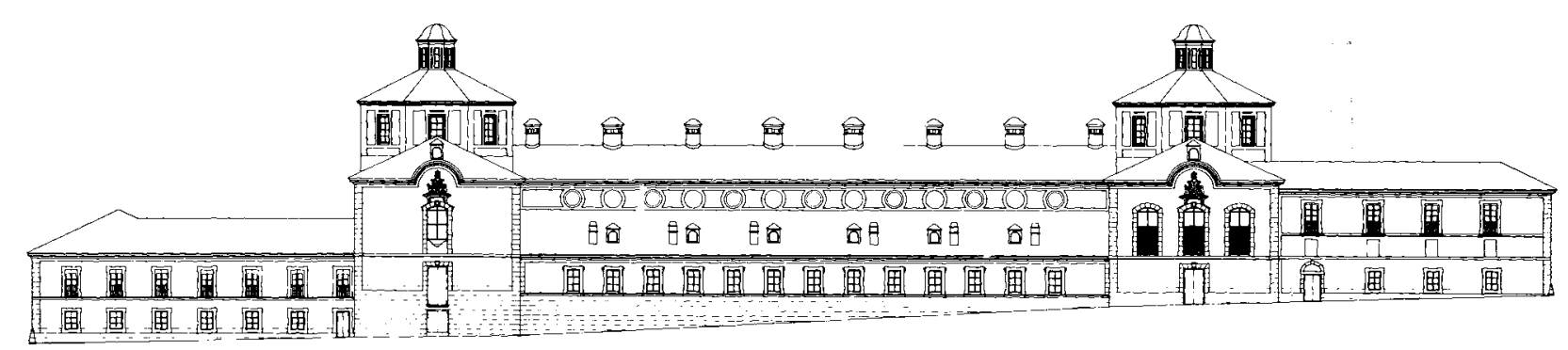

Alzado sur.

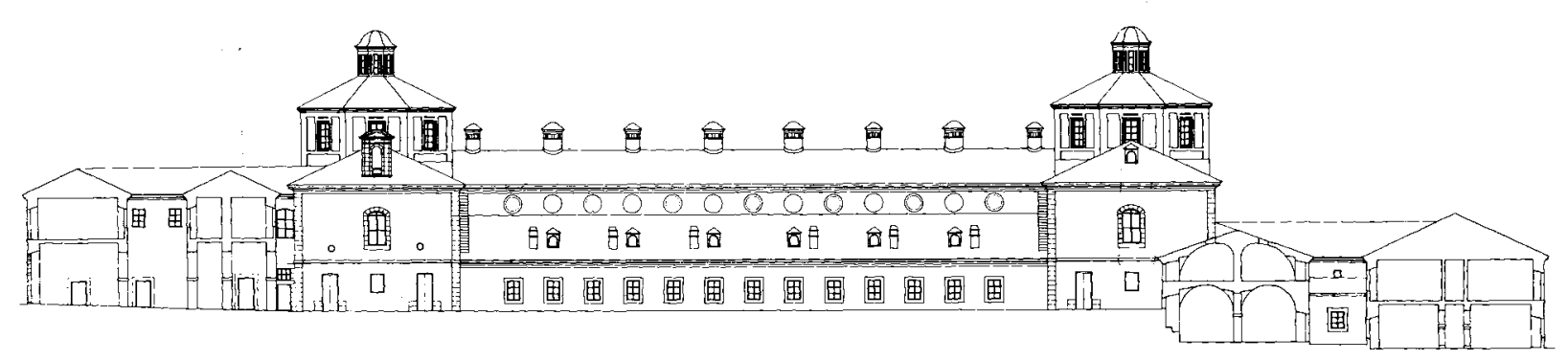

Alzado al patio.

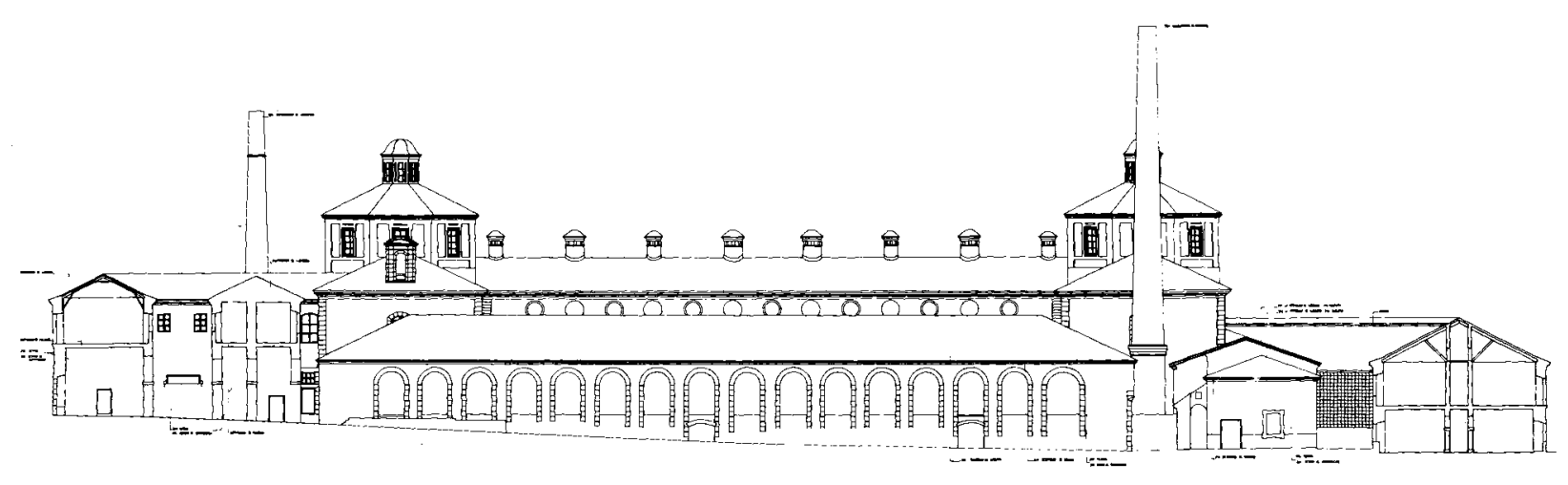




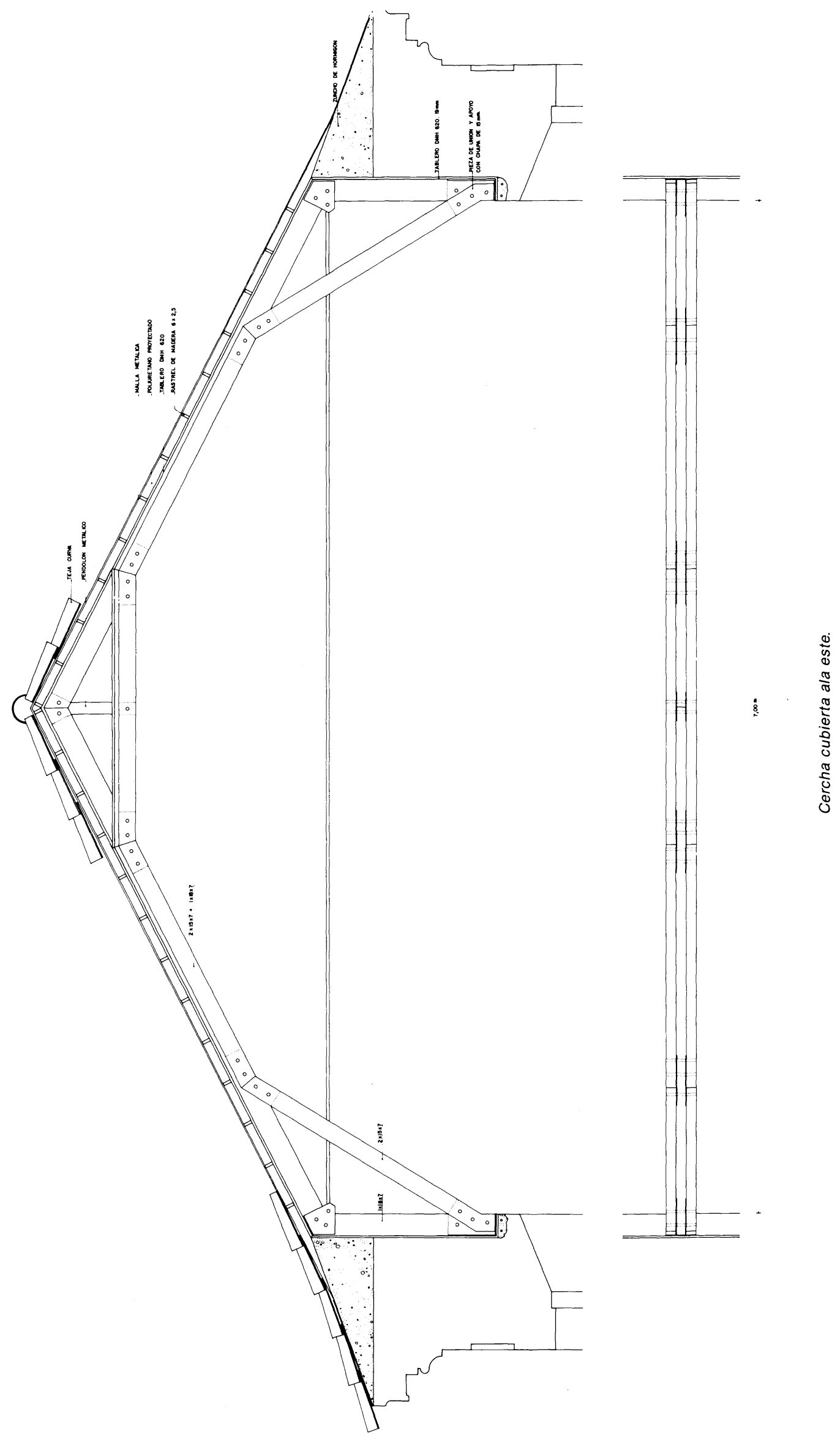




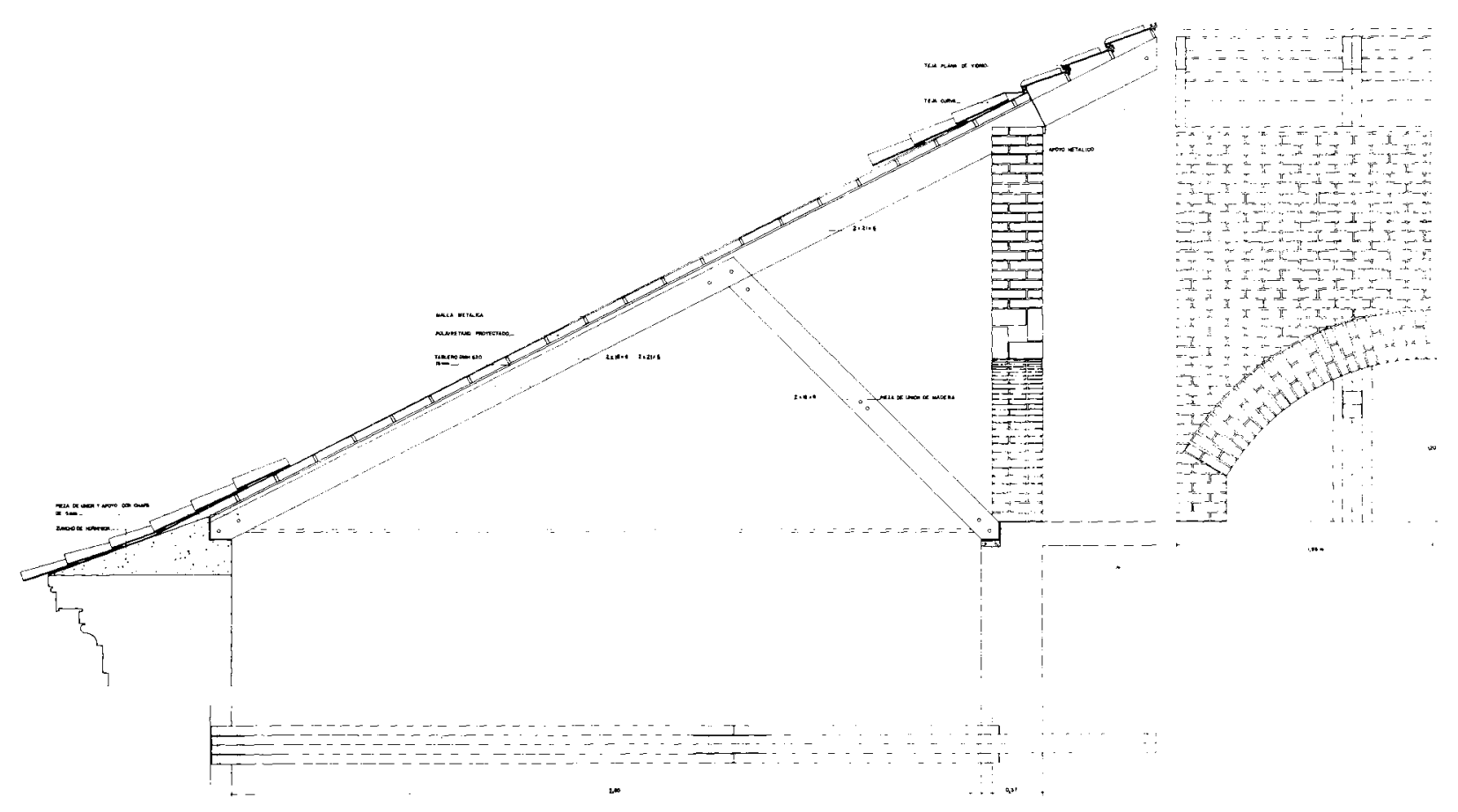

Cubierta ala oeste.

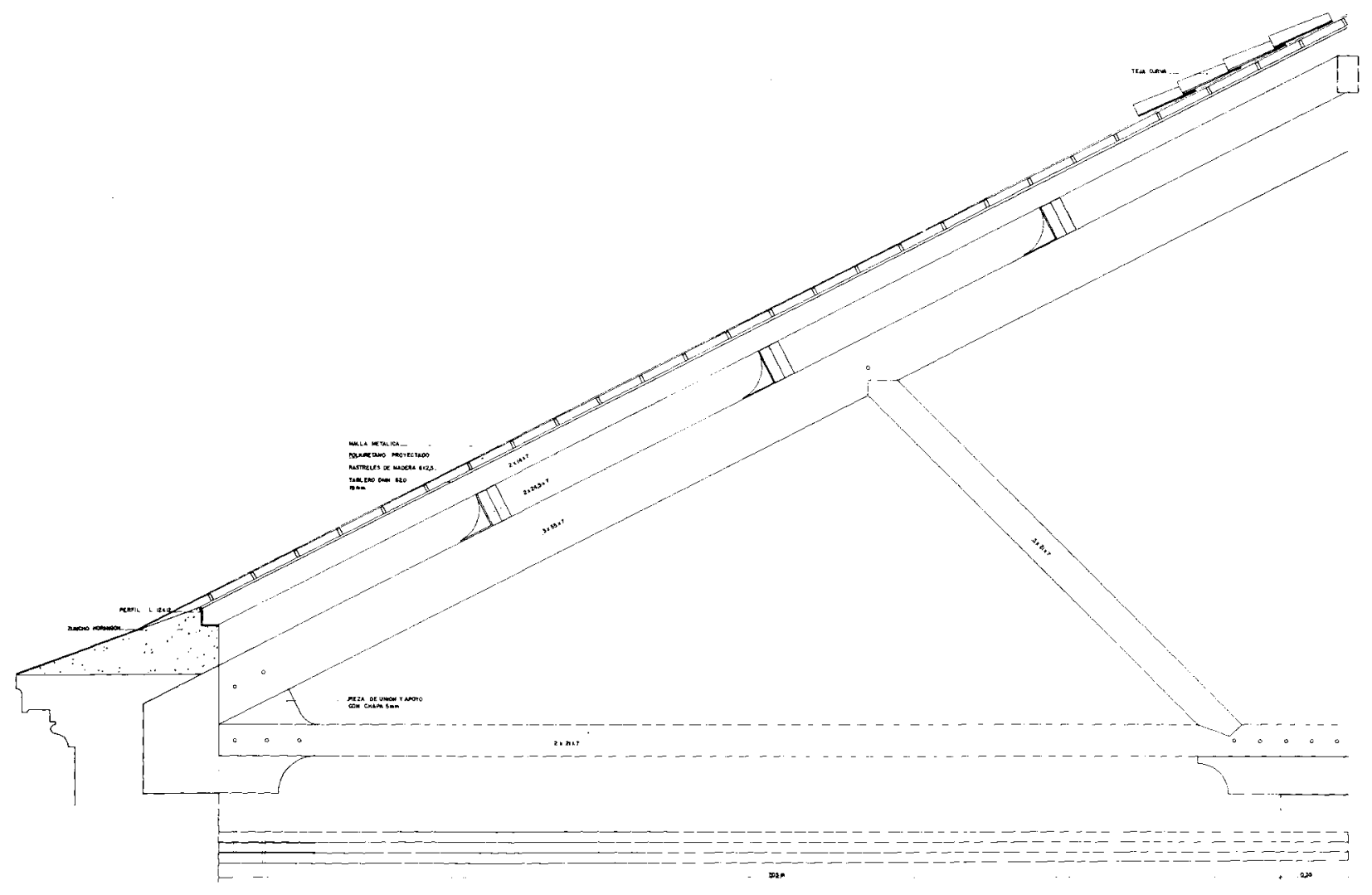




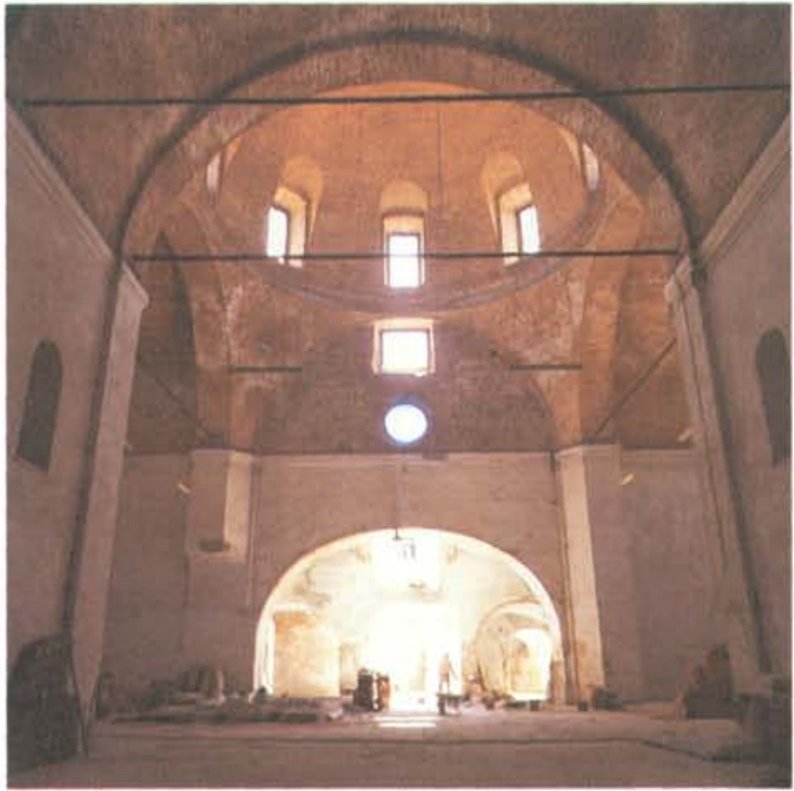

Cúpula en nave principal.

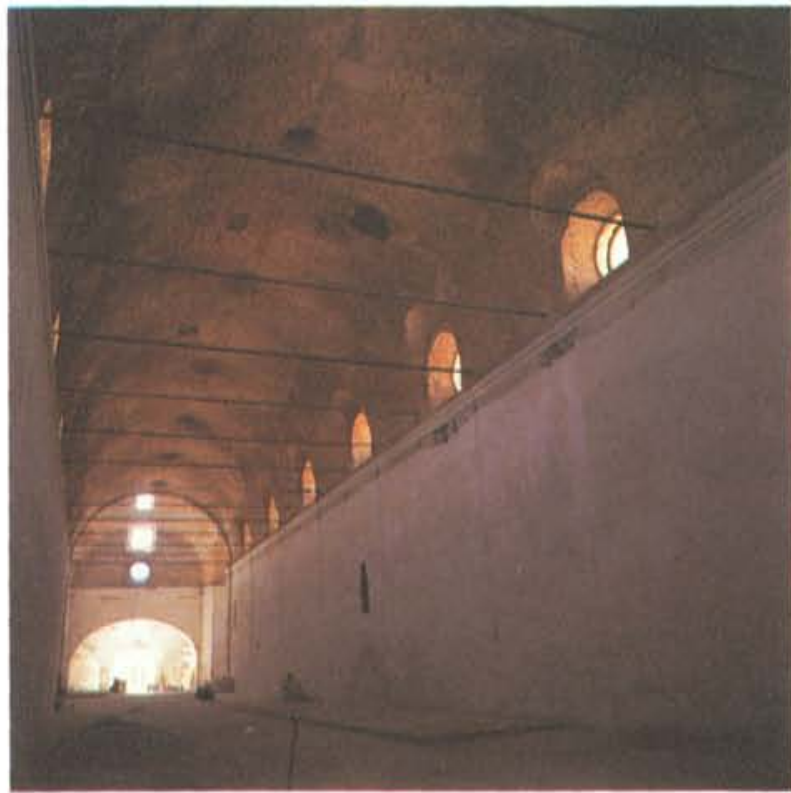

Nave principal

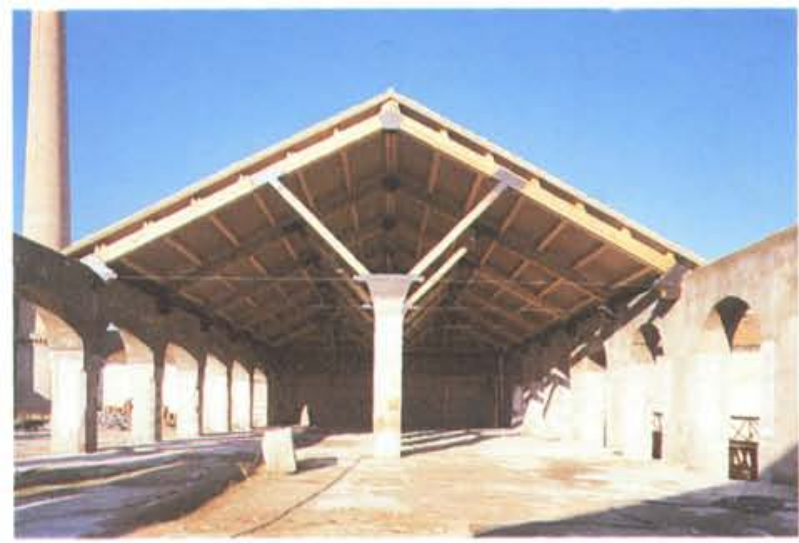

Almacén de madera.

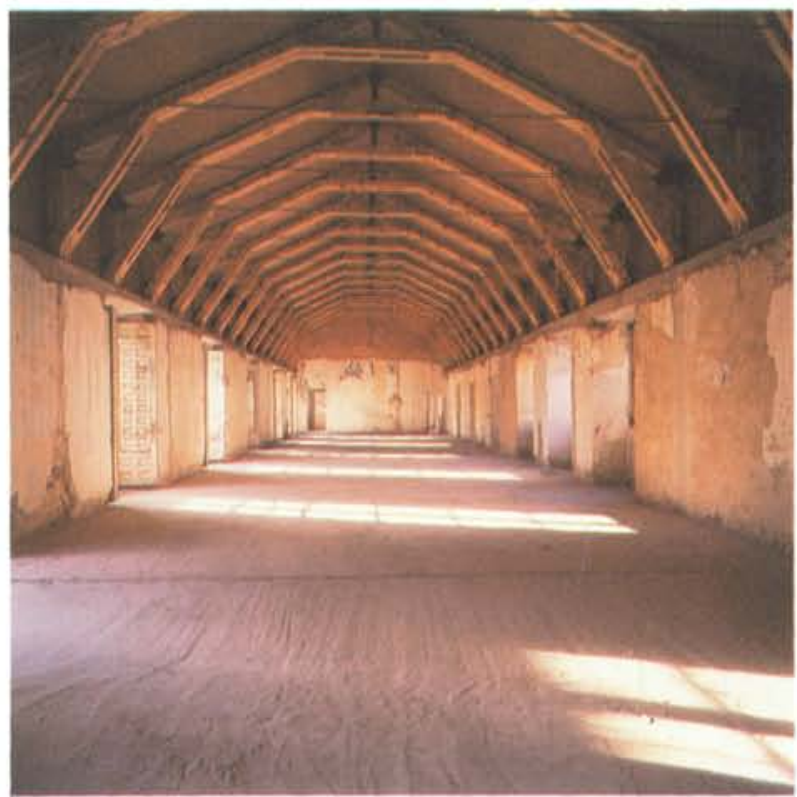

Ala este. 


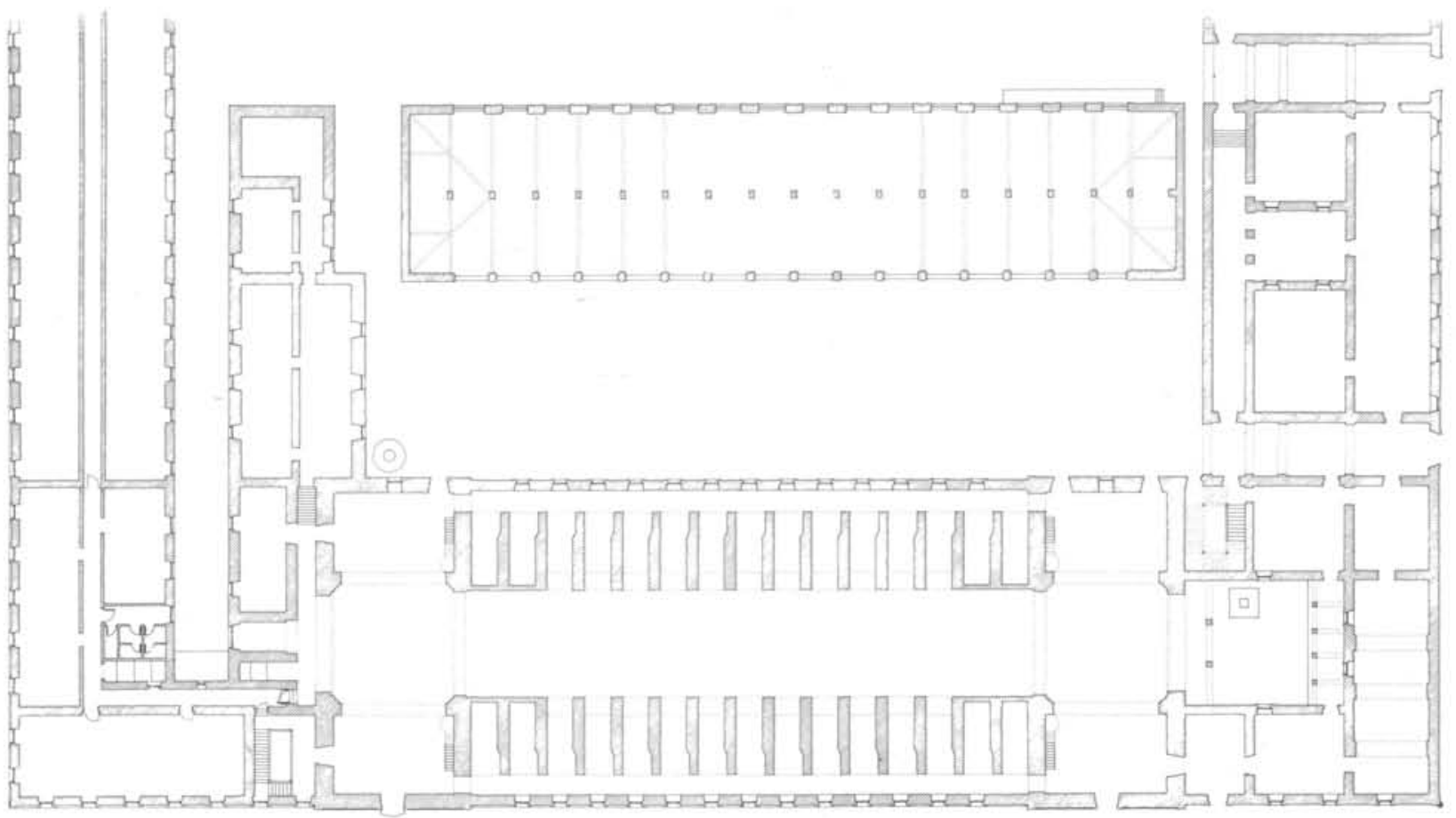

Planta.

Al quedarse vacia la fábrica comenzó un proceso de deterioro continuado y ha sido necesario actuar para su consolidación y con la finalidad de alojar en él el CENTRO NACIONAL DEL VIDRIO, que incluirá una es. cuela de Formación Artesanal, un Museo de la Fabricación del Vidrio y el Centro de Investigaciones del Vidrio.

La actuación realizada es fundamentalmente la siguiente:

1. Se han reconstruido las bóvedas desaparecidas y los sistemas de ventilación, chimeneas, buhardillas, etc., rehaciendo las cubiertas y los revocos exteriores.

2. En las naves laterales se han reconstruido las cubiertas utilizando la madera existente en éstas y en los forjados (cuando éstos se encontraban en malas condiciones). Para ello hemos utilizado un sistema de cerchas realizadas con piezas de reducido tamaño y longitud y enlazando éstas por medio de piezas metálicas. Sobre estas cerchas se colo. ca un tablero hidrófugo reforzado en su parte superior y sobre ellos el aislamiento y las tejas.

Los forjados, cuando ha sido necesario sustituirlos, se ha hecho por losas de hormigón en sección $\mathrm{Pi}$, lo que ofrece una imagen similar a la de los forjados realizados en madera. 


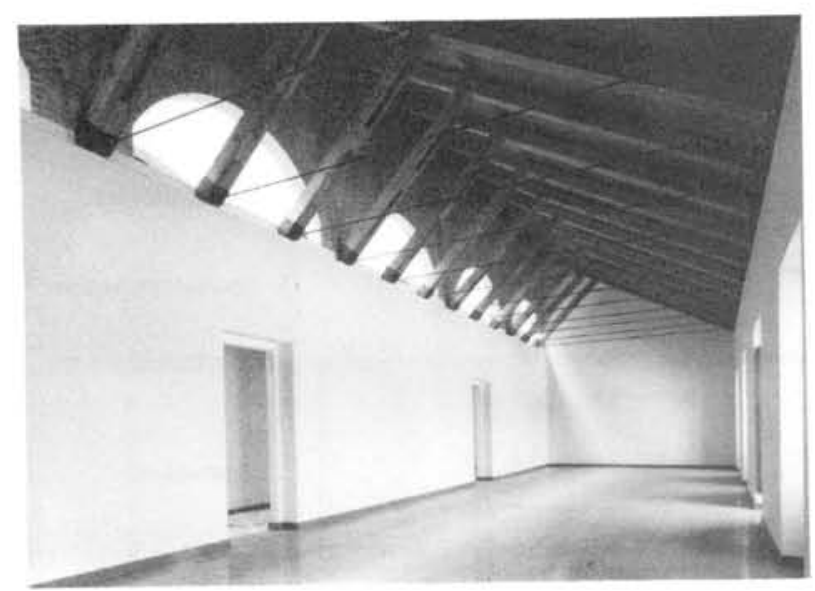

Ala oeste.

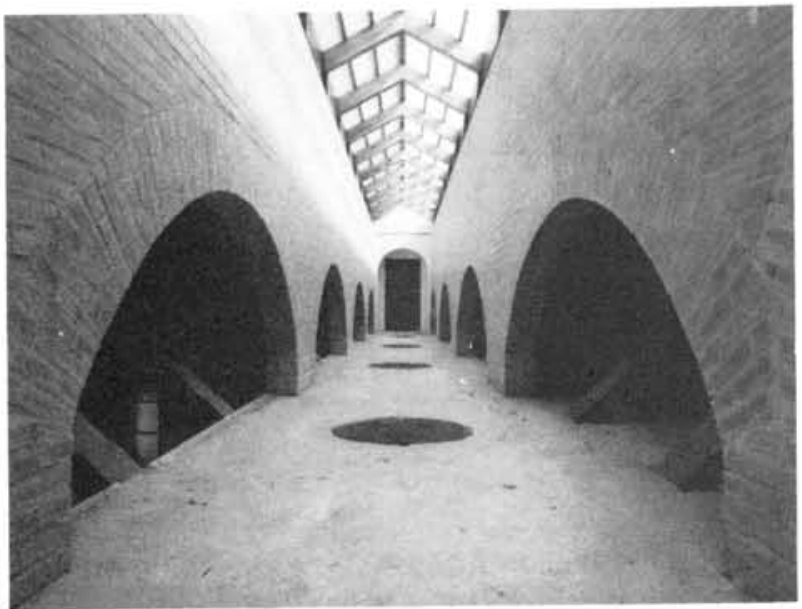

Ala oeste

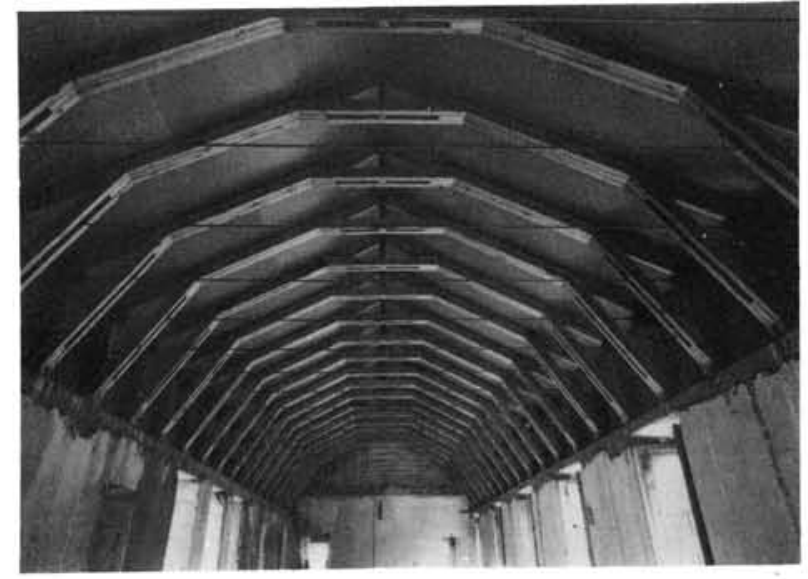

Ala este.

Se ha utilizado especialmente el diseño de los tres tipos de cerchas:

1. En el almaceń de Madera, se han reproducido integramente las cerchas primitivas sustituyendo únicamente el atirantado por otro metálico.

2. En el Ala Oeste, se han realizado unas cerchas reproduciendo un par con su jabalcón separados 1,30 $\mathrm{m}$ y que se apoyan en su cara inferior en un muro aligerado con arcos que permite la entrada de luz desde el caballete realizado con tejas de vidrio fabricadas en este mismo edificio.

3. En el Ala Este, se ha realizado una cercha del tipo de las diseñadas por Ardant igualando la longitud de los tramos y poder asi obtener una imagen similar a los espacios mudéjares. 